\title{
油菜感抗品种混播对根肿病防控效果的影响
}

\author{
郭清云 $^{1} \quad$ 汪 波 $^{1, *}$ 萠 $^{*}$ 婕 $^{1} \quad$ 张椿雨 $^{1} \quad$ 李根泽 $^{2} \quad$ 康惠仙 $^{3}$ 傅廷栋 $^{1}$ \\ 周广生 ${ }^{1}$
}

${ }^{1}$ 华中农业大学植物科技学院 / 农业部长江中游作物生理生态与耕作重点实验室, 湖北武汉 $430070{ }^{2}$ 云南省农业科学院经济作物研 究所, 云南昆明 $650205 ;^{3}$ 临沧市临翔区农业技术推广站, 云南临翔 677000

摘 要: 近年来, 油菜根肿病危害在我国呈蔓延趋势, 主要原因是化学防治成本高且效果差。实际生产中, 种植抗性 品种是最经济、最有效的措施。不同抗感品种混播, 在保证产量稳定的前提下可减轻对病原菌小种的选择压, 从而稳 定病原菌种群结构, 延长抗性品种使用寿命。本试验在安徽绩溪、云南临翔 2 个油菜根肿病严重发生区域, 选择 2 组互为近等基因系的感病、抗病的油菜品种, 按不同比例混播(感病、抗病比例分别为 10:0、1:9、2:8、3:7 和 0:10), 在 根肿病明显发生后调查发病率等指标。结果表明: 不同比例感病、抗病油菜品种混播均降低了根肿病发病率和病情 指数, 并稳定油菜产量和品质; 且油菜发病株率随抗病品种的比例下降而升高, 但均低于理论发病率; 不同抗性组 合间混播的相对防效(REM)均低于 1, 且随着作物生育期的推迟呈现下降趋势。以上结果表明, 油菜感抗品种混播对 根肿病有较好的防控效果。本研究主要在大田条件下明确了 2 组不同抗感近等基因组合混播对油菜根肿病的防治效 果, 可为油菜根肿病防治提供思路和对策。

关键词: 油菜; 根肿病; 近等基因系; 混播

\section{Controlling efficiency against clubroot disease of rapeseed by mixed-cropping of susceptible and resistant cultivars}

GUO Qing-Yun ${ }^{1}$, WANG Bo ${ }^{1, *}$, KUAI Jie ${ }^{1}$, ZHANG Chun-Yu ${ }^{1}$, LI Gen-Ze ${ }^{2}$, KANG Hui-Xian ${ }^{3}$, FU Ting-Dong ${ }^{1}$, and ZHOU Guang-Sheng ${ }^{1}$

\footnotetext{
${ }^{1}$ Key Laboratory of Crop Physiology, Ecology and Cultivation (The Middle Reaches of the Yangtze River) of Ministry of Agriculture / College of Plant Science and Technology, Huazhong Agricultural University, Wuhan 430070, Hubei, China; ${ }^{2}$ Industrial Crop Research Institute, Yunnan Academy of Agricultural Sciences, Kunming 650205, Yunnan, China; ${ }^{3}$ Linxiang Agricultural Technique Extension Station, Lincang City, Linxiang 677000, Yunnan, China
}

\begin{abstract}
In recent years, rapeseed clubroot disease has spread widely in China, and the cost of the chemical control is high while the efficiency is low. Using resistant varieties is the most economical and efficient way to control this disease. Mixed-cropping different resistant varieties can improve the control efficiency of crop diseases, but the research on it has not been reported. In two naturally-infested locations of clubroot diseases in Jixi of Anhui province and Linxiang of Yunnan province, two pairs of susceptible and resistant cultivars were used (highly resistant variety Huashuang 5R mixed with highly susceptible variety Huashuang 5 and highly resistant variety Huayouza 62R mixed with highly susceptible variety Huayouza 62). Seeds of each pair were mixed at different ratios (10:0, 1:9, 2:8, 3:7, and 0:10) and sown in the two locations respectively. The incidence rate was surveyed after occurrence of clubroot disease. The mixed-cropping at different ratios of susceptible and resistant cultivars decreased the incidence and disease index of clubroot disease, and stabilized the yield and quality of rapeseed. The actual incidence rate in the mixed cropping treatment increased with the decrease of resistant cultivar proportion, which was from $5.7 \%$ to $17.1 \%$ at Jixi and
\end{abstract}

\footnotetext{
本研究由国家重点研发计划项目(2018YFD1000900), 湖北省技术创新专项重大项目(2017ABA064)和中央高校基本科研业务费 (2662017JC005)项目资助。

This study was supported by the National Key Research and Development Program of China (2018YFD1000900), the Technological Innovation Major Project of the Science and Technology Department of Hubei Province (2017ABA064), and the Fundamental Research Funds for the Central Universities (2662017JC005).

*通信作者(Corresponding author): 汪波, E-mail: wangbo@mail.hzau.edu.cn

第一作者联系方式: E-mail: 1278245883@qq.com

Received (收稿日期): 2019-09-28; Accepted (接受日期): 2019-12-26; Published online (网络出版日期): 2020-01-13.

URL: http://kns.cnki.net/kcms/detail/11.1809.S.20200113.1400.002.html
} 
from $4.4 \%$ to $32.1 \%$ at Linxiang for Huashuang $5 \mathrm{R} /$ Huashang 5 , while from $5.7 \%$ to $18.6 \%$ at Jixi and from $2.1 \%$ to $12.0 \%$ at Linxiang for Huayouza 62R/Huayouza 62 respectively, and significantly lower than the theoretical disease incidence rate. The relative effectiveness of mixture of the two pairs of cultivars were lower than 1 , which indicates that the mixed-cropping of susceptible and resistant cultivars has positive effect. This study mainly clarified the control effect of mixed-cropping two different Near-isogenic lines with different resistance levels on clubroot disease, which can provide new ideas and countermeasures for the prevention of clubroot disease.

Keywords: rapeseed; clubroot disease; near-isogenic lines; mixed-cropping

根肿病是由芸薹根肿菌 (Plasmodiophora brassicae Woronin)引起的一种土传病害, 是十字花科作 物最具破坏性的病害之一 ${ }^{[1]}$ 。根肿菌在土壤中一般 以休眠孢子形态存在。萌发后以活体营养在寄主体 内繁殖。根肿菌生活史主要分为初侵染阶段(根毛侵 染)和再侵染阶段(皮层侵染) ${ }^{[2]}$ 。休眠孢子在适宜条 件下, 受十字花科植物根系分泌物诱导萌发后释放 出初生游动孢子, 游向根毛完成初侵染过程并产生 次级游动孢子。次级游动孢子直接侵染根和下胚轴 的皮层组织完成再侵染过程。次级游动狍子成熟后 又释放休眠孢子到土壤中, 等待下一次萌发。整个 侵染过程中, 根肿菌与寄主互作引起寄主根部生长 素和细胞分裂素代谢紊乱、根细胞结构破坏, 形成 肉眼可见的根瘤 ${ }^{[3-4]}$ 。

包括中国在内的 60 多个国家均有根肿病的危害, 导致十字花科作物产量大幅下降 ${ }^{[5]}$ 。我国油菜面积 居世界首位, 但目前油菜根肿病危害面积已突破 66.7 万公顷, 主要分布于四川、云南、安徽、湖北 等省份 ${ }^{[6]}$, 已对我国油菜产业构成严重威胁。当前, 油菜根肿病的防控措施主要包括农业防治(如石灰、 轮作、诱饵作物、迟播 $)^{[7-10]}$ 、化学农药防治(如氟啶

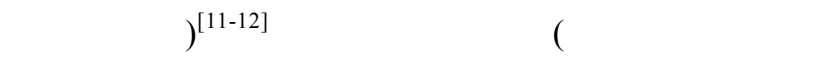
芽孢杆菌) $)^{[13-14]}$ 及种植抗性品种等。其中, 种植抗性 品种是最经济、最有效的防治措施。国内外学者在 油菜根肿病抗性资源筛选及抗根肿病基因遗传定位 与克隆上做了大量研究 ${ }^{[15]}$ 。我国研究者培育出含不 同的抗性位点的华双 $5 \mathrm{R}^{[16]}$ 和华油杂 $62 \mathrm{R}$ 的抗性品 种对长江流域油菜产区优势生理小种(4 号小种)具 有良好抗性。但根肿菌休眠狍子的半衰期为 3.6 年 ${ }^{[17]}$, 意味着在没有种植易感寄主情况下, 需 18 年才能减 少到 3\%的田间孢子种群, 加之根肿菌小种存在分化 现象, 长时间种植单一抗病品种其抗性会因生理小 种变异而侵蚀 ${ }^{[18]}$, 故抗性丧失是油菜根肿病防控的 潜在危机。

利用多系品种混合种植可有效防控作物病害, 如小麦条锈病 ${ }^{[19]}$ 、水稻稻瘟病 ${ }^{[20]}$ 等。Hariri 等 ${ }^{[21]}$ 利 用 1 个感病和 1 个抗病品种以 $1: 1$ 和 1: 3 比例混
播, 均减轻了小麦花叶病感染率。以抗、感组合混 播防治小麦条锈病效应较好 ${ }^{[22]}$ 。混播控制病害发生 有密度效应 ${ }^{[23]}$ 、阻挡效应 ${ }^{[24]}$ 和抗性诱导效应 ${ }^{[25]} 3$ 种 机制。混播在控制病害前提下，还能避免病原菌小 种的高度选择, 稳定病原菌群体结构 ${ }^{[26]}$, 从而延长 抗病品种抗性。以上研究表明, 不同抗性品种混播 对某些病害的防控具有较好的效果, 但尚未见油菜 根肿病相关研究报道。本研究利用抗病和感病品种 混播, 探讨混播在油菜根肿病防控中的可行性。

\section{1 材料与方法}

\section{1 试验材料}

2 组感根肿病和抗根肿病的近等基因系油菜品 种, 分别为华双 $5 \mathrm{R}$ 和华双 5 号(华双 $5 \mathrm{R}$ 含抗 4 号生 理小种抗病位点 $P b B a 8.1$, 抗源来源于芜菁, 为显性 抗病, 华双 5 号则不含相应抗病位点); 华油杂 $62 \mathrm{R}$ 和华油杂 62 (华油杂 $62 \mathrm{R}$ 含抗 4 号生理小种抗病位 点 $C R b$, 抗源来源于大白菜, 为不完全抗性, 而华油 杂 62 则不含相应抗病位点)。

\section{2 试验设计}

于 2017-2018 年在根肿菌优势小种均为 4 号生 理小种的安徽宣城市绩溪县根肿病病圑 $\left(30.07^{\circ} \mathrm{N}\right.$, $\left.118.60^{\circ} \mathrm{E}\right)$ 及云南临沧市临翔区根肿病病圃 $\left(23.88^{\circ} \mathrm{N}\right.$, $100.08^{\circ} \mathrm{E}$ )进行试验。随机区组设计, 每组设近等基 因系材料 5 个处理, 包括 2 个感病、抗病品种单播 (感、抗比例分别为 $10 ： 0$ 和 $0 ： 10$ )、3 个播种量比 例的感病、抗病品种混播(感、抗比例分别为 $1: 9$ 、 2:8 和 3：7)。小区面积 $20 \mathrm{~m}^{2}, 3$ 次重复。每公顷用 种量均为 $3.75 \mathrm{~kg}$, 混播处理中各品种组成按重量比 混合。2017 年 9 月 30 日与 2017 年 10 月 10 日分别 在两地以 $25 \mathrm{~cm}$ 的行距人工条播。油菜全生育期不 间苗, 除正常施肥外, 不施用任何药剂; 其他田间 管理按常规方法进行。

\section{3 测定项目与方法}

1.3.1 发病率根据当地发病规律, 四叶至五叶 期开始定期调查根肿病发病情况。待植株根部有肿 瘤出现, 调查发病率。各小区均连续调查 3 行植株, 
统计总株数、发病株数, 计算发病率。不同试验点 根肿菌菌源量及气候差异, 安徽绩溪试验点初次发 病时间为八叶至十叶期, 云南临翔试验点初次发病 时间为油菜蕾薹期。

$$
\text { 发病率 }=\frac{\text { 发病株数 }}{\text { 调查总株数 }} \times 100 \%
$$

混播处理理论发病率 $(\%)=$ 感病品种比例 $\times$ 感 病品种单播发病率 $(\%)+$ 抗病品种比例 $\times$ 抗病品种单 播发病率 $(\%)$

\subsection{2 病情指数发病率高低不能准确根肿病危} 害程度, 故采用 Kuginuki 方法 ${ }^{[27]}$ 将根瘤分级, 计算 病情指数。 0 级: 无症状; 1 级: 有少量小根瘤, 根瘤 体积小于根系的 $1 / 3 ; 2$ 级: 中度结瘤, 根瘤体积是根 系的 $1 / 3$ 至 $1 / 2 ; 3$ 级: 重度结瘤, 根瘤体积超过根系 $2 / 3$ 。

$$
\text { 病情指数 }=\frac{\left.\sum \text { (各级发病株数 } \times \text { 各级代表数 }\right)}{\text { 调查总株数 } \times 3} \times 100
$$

\subsection{3 相对防效 利用相对防效(relative effec-} tiveness of mixture, REM)评价混播相对单播的防控 效果 ${ }^{[28]}$ 。REM 值越小, 效果越明显。REM $<1$ 时, 混 播有效; REM $\geq 1$ 时混播无效。

$$
\mathrm{REM}=\frac{D}{\sum\left(D_{i} \times P_{i}\right) / \sum P_{i}}
$$

式中, $D$ 表示感、抗品种混播发病率, $D_{i}$ 表示感病或 抗病品种单播发病率, $P_{i}$ 表示感病或抗性品种各自 所占比例。

1.3.4 产量与产量构成终花后 $35 \mathrm{~d}$, 从各小区 连续取样 10 株, 考察单株角果数、每角果粒数和千粒 重。油菜 $80 \%$ 左右角果皮颜色呈淡黄色, 油菜籽粒变 褐时, 收获并测定小区产量, 调查成熟期实际株数。

\subsection{5 䊏粒品质 用近红外光谱分析仪(BRUKER} 公司生产的 VECTOR 22/N 系列)测定籽粒含油量
和蛋白质含量; 用全自动氨基酸分析仪检测籽粒中 各游离氨基酸含量。

\section{4 数据分析}

用 SPSS 11.0 统计软件进行方差分析, 以最小显 著差法(least significant difference, LSD)检验显著性, 显著性水平均设为 0.05 。

\section{2 结果与分析}

\section{1 不同比例混播对根肿病发生的影响}

2.1 .1 发病率及比病情指数 由表 1 可知, 2 个抗 病品种在各试验点均表现出根肿病抗性, 但不同感 (抗)病品种在 2 个试验点发病情况均存在差异。在安 徽省绩溪试验点, 华双 5 号和华油杂 62 两个感病品 种单播(10：0)时, 油菜八至十叶期发病率达 100\%, 华双 $5 \mathrm{R}$ 和华油杂 $62 \mathrm{R}$ 两个抗病品种单播 $(0 ： 10)$ 时, 发病率均为 0 ; 在云南省临翔试验点, 2 个感病品种 单播 (10: 0), 八叶至十叶期发病率分别为 $32.1 \%$ 、 $77.5 \%, 2$ 个抗病品种单播时 $(0 ： 10)$, 发病率分别为 $2.0 \%$ 、 0 。可以看出, 感病品种单播时, 绩溪试验点的发病 率高于临翔试验点。

华双 5 号和华双 $5 R$ 及华油杂 62 和华油杂 $62 R$ 两组近等基因系的感、抗品种按比例混播时, 2 个试 验点实际发病率及病情指数均随混播比例提高而增 加, 但与理论发病率相比, 群体实际发病率变化存 在差异(表 1)。如绩溪试验点, 华双 5 号和华双 $5 \mathrm{R}$ 按 3: 7 比例混播时, 八叶至十叶期及蕾薹期实际发 病率分别为 $17.1 \% 、 1.4 \%$, 均高于华双 $5 \mathrm{R}$ 单播 0 及 $0.3 \%$ 的发病率，但却均低于 $30.0 \%$ 及 $30.2 \%$ 的理论 值; 而华油杂 62 和华油杂 $62 \mathrm{R}$ 按 3：7 比例混播时, 八叶至十叶期和蕾䔇期的实际发病率为 $18.6 \%$ 和 $12.4 \%$ ，也均低于 $30 \%$ 的理论发病率，说明这 2 个近 等基因系感、抗品种混播在 2 个时期均有明显效果。

\begin{tabular}{|c|c|c|c|c|c|c|c|c|c|c|c|c|c|c|c|c|}
\hline \multirow{2}{*}{$\begin{array}{l}\text { 地点 } \\
\text { Place }\end{array}$} & \multirow{2}{*}{$\begin{array}{c}\text { 组合 } \\
\text { Combination }\end{array}$} & \multirow{2}{*}{$\begin{array}{l}\text { 比例 } \\
\text { Ratio }\end{array}$} & \multicolumn{2}{|c|}{ 发病率 $^{\mathrm{A}}$} & \multicolumn{4}{|c|}{ 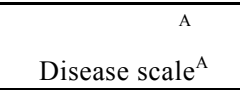 } & \multirow{2}{*}{$\begin{array}{c}\text { 病情 } \\
\text { 指数 }^{\mathrm{A}} \\
\text { Disease } \\
\text { index }^{\mathrm{A}}\end{array}$} & \multicolumn{2}{|c|}{$\begin{array}{c}\text { 发病率 }^{\mathrm{B}} \\
\text { Incidence rate }^{\mathrm{B}}(\%)\end{array}$} & \multicolumn{4}{|c|}{ 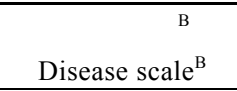 } & \multirow{2}{*}{$\begin{array}{c}\text { 病情 } \\
\text { 指数 } \\
{ }^{B} \\
\text { Disease } \\
\text { index }^{B}\end{array}$} \\
\hline & & & $\begin{array}{c}\text { 理论值 } \\
\text { Theoretical }\end{array}$ & $\begin{array}{l}\text { 实际值 } \\
\text { Actual } \\
\end{array}$ & 0 & 1 & 2 & 3 & & $\begin{array}{c}\text { 理论值 } \\
\text { Theoretical }\end{array}$ & $\begin{array}{l}\text { 实际值 } \\
\text { Actual } \\
\end{array}$ & 0 & 1 & 2 & 3 & \\
\hline \multirow{5}{*}{$\begin{array}{l}\text { 绩溪 } \\
\text { Jixi }\end{array}$} & 华双 5 号:华双 $5 \mathrm{R}$ & $0: 10$ & 0 & $0 \mathrm{c}$ & 30 & 0 & 0 & 0 & $0 \mathrm{~d}$ & 0.3 & $0.3 \mathrm{~b}$ & 30 & 0 & 0 & 0 & $0 \mathrm{~d}$ \\
\hline & Huashuang 5(S): & $1: 9$ & 10.0 & $5.7 \mathrm{c}$ & 28 & 0 & 2 & 0 & $4.4 \mathrm{c}$ & 10.3 & $0.6 \mathrm{~b}$ & 28 & 0 & 1 & 1 & $5.6 \mathrm{~b}$ \\
\hline & & $2: 8$ & 20.0 & $16.1 \mathrm{~b}$ & 25 & 1 & 1 & 3 & $13.3 \mathrm{~b}$ & 20.2 & $0.8 \mathrm{~b}$ & 28 & 1 & 0 & 1 & $4.4 \mathrm{c}$ \\
\hline & & $3: 7$ & 30.0 & $17.1 \mathrm{~b}$ & 25 & 10 & 3 & 1 & $11.1 \mathrm{~b}$ & 30.2 & $1.4 \mathrm{~b}$ & 29 & 0 & 0 & 1 & $3.3 \mathrm{c}$ \\
\hline & & 10:0 & 100.0 & $100.0 \mathrm{a}$ & 0 & 0 & 2 & 28 & $97.8 \mathrm{a}$ & 100.0 & $100.0 \mathrm{a}$ & 0 & 0 & 0 & 30 & $100.0 \mathrm{a}$ \\
\hline
\end{tabular}

表 1 不同处理条件下的根肿病发病情况

Table 1 Incidence under different treatments in different plaeas 
(续表 1)

\begin{tabular}{|c|c|c|c|c|c|c|c|c|c|c|c|c|c|c|c|c|}
\hline \multirow{2}{*}{$\begin{array}{l}\text { 地点 } \\
\text { Place }\end{array}$} & \multirow{2}{*}{$\begin{array}{c}\text { 组合 } \\
\text { Combination }\end{array}$} & \multirow{2}{*}{$\begin{array}{l}\text { 比例 } \\
\text { Ratio }\end{array}$} & \multicolumn{2}{|c|}{ 发病率 $^{\mathrm{A}}$} & \multicolumn{4}{|c|}{ 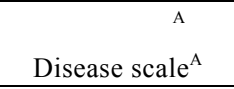 } & \multirow{2}{*}{$\begin{array}{c}\text { 病情 } \\
\text { 指数 }^{\mathrm{A}} \\
\text { Disease } \\
\text { index }^{\mathrm{A}}\end{array}$} & \multicolumn{2}{|c|}{$\begin{array}{c}\text { 发病率 } \\
{ }^{\mathrm{B}} \\
\text { Incidence } \text { rate }^{\mathrm{B}}(\%)\end{array}$} & \multicolumn{4}{|c|}{ 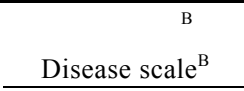 } & \multirow{2}{*}{$\begin{array}{c}\text { 病情 } \\
\text { 指数 } \\
{ }^{B} \\
\text { Disease } \\
\text { index }^{B}\end{array}$} \\
\hline & & & $\begin{array}{c}\text { 理论值 } \\
\text { Theoretical }\end{array}$ & $\begin{array}{l}\text { 实际值 } \\
1 \text { Actual } \\
\end{array}$ & 0 & 1 & 2 & 3 & & $\begin{array}{c}\text { 理论值 } \\
\text { Theoretical }\end{array}$ & $\begin{array}{l}\text { 实际值 } \\
\text { Actual } \\
\end{array}$ & 0 & 1 & 2 & 3 & \\
\hline \multirow{15}{*}{$\begin{array}{c}\text { 临翔 } \\
\text { Linxiang }\end{array}$} & 华油杂 62 号: & $0: 10$ & 0 & $0 \mathrm{e}$ & 30 & 0 & 0 & 0 & $0 \mathrm{e}$ & 0 & $0 \mathrm{~d}$ & 30 & 0 & 0 & 0 & $0 \mathrm{~d}$ \\
\hline & $\begin{array}{c}\text { 华油杂 } 62 \text { R } \\
\text { Huayouza 62(S): }\end{array}$ & $1: 9$ & 10.0 & $5.7 \mathrm{~d}$ & 28 & 1 & 1 & 0 & $3.3 \mathrm{~d}$ & 10.0 & $3.6 \mathrm{c}$ & 29 & 0 & 1 & 0 & $2.2 \mathrm{c}$ \\
\hline & Huayouza 62R(R) & $2: 8$ & 20.0 & $10.9 \mathrm{c}$ & 27 & 2 & 1 & 0 & $4.4 \mathrm{c}$ & 20.0 & $4.1 \mathrm{c}$ & 29 & 0 & 1 & 0 & $2.2 \mathrm{c}$ \\
\hline & & $3: 7$ & 30.0 & $18.6 \mathrm{~b}$ & 25 & 4 & 1 & 1 & $10.0 \mathrm{~b}$ & 30.0 & $12.4 \mathrm{~b}$ & 27 & 2 & 1 & 0 & $4.5 \mathrm{~d}$ \\
\hline & & 10:0 & 100.0 & $100.0 \mathrm{a}$ & 0 & 0 & 0 & 30 & $100.0 \mathrm{a}$ & 100.0 & $100.0 \mathrm{a}$ & 0 & 0 & 0 & 30 & $100.0 \mathrm{a}$ \\
\hline & 华双 5 号:华双 $5 \mathrm{R}$ & $0: 10$ & 2.0 & $2.0 \mathrm{c}$ & 29 & 1 & 0 & 0 & $1.0 \mathrm{c}$ & 2.2 & $2.2 \mathrm{~b}$ & 29 & 0 & 0 & 1 & $3.3 \mathrm{~d}$ \\
\hline & $\begin{array}{l}\text { Huashuang 5(S): } \\
\text { Huashuang 5R(R) }\end{array}$ & $1: 9$ & 5.0 & $4.4 \mathrm{bc}$ & 28 & 0 & 1 & 1 & $5.6 \mathrm{~b}$ & 8.1 & $4.4 \mathrm{~b}$ & 29 & 0 & 0 & 1 & $3.3 \mathrm{~d}$ \\
\hline & & $2: 8$ & 8.0 & $7.2 \mathrm{bc}$ & 28 & 0 & 0 & 2 & $6.7 \mathrm{~b}$ & 14.0 & $7.8 \mathrm{~b}$ & 28 & 0 & 0 & 2 & $6.7 \mathrm{c}$ \\
\hline & & $3: 7$ & 11.0 & $10.1 \mathrm{~b}$ & 27 & 1 & 1 & 1 & $6.7 \mathrm{~b}$ & 20.0 & $11.1 \mathrm{~b}$ & 27 & 0 & 1 & 2 & $8.9 \mathrm{~b}$ \\
\hline & & 10:0 & 32.1 & $32.1 \mathrm{a}$ & 20 & 0 & 0 & 10 & $33.3 \mathrm{a}$ & 61.1 & $61.1 \mathrm{a}$ & 12 & 0 & 1 & 17 & $58.9 \mathrm{a}$ \\
\hline & 华油杂 62 号: & $0: 10$ & 0 & $0 \mathrm{e}$ & 30 & 0 & 0 & 0 & $0 \mathrm{e}$ & 8.4 & $8.4 \mathrm{~d}$ & 27 & 1 & 2 & 0 & $5.6 \mathrm{~d}$ \\
\hline & $\begin{array}{c}\text { 华油杂 } 62 \text { R } \\
\text { Huayouza 62(S): }\end{array}$ & $1: 9$ & 7.7 & $2.1 \mathrm{~d}$ & 29 & 1 & 0 & 0 & $1.1 \mathrm{~d}$ & 16.5 & $12.0 \mathrm{c}$ & 26 & 2 & 1 & 1 & $7.8 \mathrm{c}$ \\
\hline & Huayouza 62R(R) & $2: 8$ & 15.5 & $8.0 \mathrm{c}$ & 28 & 2 & 0 & 0 & $2.2 \mathrm{c}$ & 24.5 & $13.4 \mathrm{c}$ & 26 & 1 & 2 & 1 & $8.9 \mathrm{~b}$ \\
\hline & & $3: 7$ & 23.3 & $12.0 \mathrm{~b}$ & 26 & 3 & 1 & 0 & $5.6 \mathrm{~b}$ & 32.6 & $16.0 \mathrm{~b}$ & 25 & 3 & 1 & 1 & $8.9 \mathrm{~b}$ \\
\hline & & 10:0 & 77.5 & $77.5 \mathrm{a}$ & 7 & 0 & 1 & 22 & $75.6 \mathrm{a}$ & 88.9 & $88.9 \mathrm{a}$ & 3 & 0 & 27 & 27 & $90.0 \mathrm{a}$ \\
\hline
\end{tabular}

A 组数据绩溪和临翔第 1 次调查时间分别为苗期(八至十叶期)和蕾薹期; B 组数据绩溪和临翔第 2 次调查时间分别为蕾薹期和成熟期。 同一列平均值后的字母不同表示在 $P<0.05$ 水平差异显著。 $\mathrm{S}$ : 感病; R: 抗病。

A: at the first investigation period of seedling stage ( 8 to 10 leaves) in Jixi, and bud stage in Linxiang. B: at the second investigation period of bud stage in Jixi, and maturation stage in Linxiang. Means followed by different lowercase letters in the same column are significantly different at the 0.05 probability level. S: susceptible; R: resistant.

2.1.2 相对混播效果 由表 2 可知, 2 组近等基因 系混播的 REM 值均小于 1, 说明感、抗品种混播对油 菜根肿病的防控均有较好的效果; 进一步比较发现,
与第 1 次调查相比, 2 组近等基因系混播后, 第 2 次调 查时的 REM 值呈下降的趋势, 说明感病、抗病品种混 播后，随着生育期的推迟混播效应逐渐发挥作用。

\section{表 2 不同混播处理下的相对防效(REM)}

Table 2 Relative effectiveness of mixture (REM) under different treatments

\begin{tabular}{|c|c|c|c|c|c|}
\hline \multirow{2}{*}{$\begin{array}{c}\text { 组合 } \\
\text { Combination }\end{array}$} & \multirow{2}{*}{$\begin{array}{l}\text { 比例 } \\
\text { Ratio }\end{array}$} & \multicolumn{2}{|c|}{ 绩溪 Jixi } & \multicolumn{2}{|c|}{ 临翔 Linxiang } \\
\hline & & 苗期 Seedling & 蕾薹期 Budding & 蕾薹期 Budding & 成熟期 Maturation \\
\hline 华双 5 号:华双 $5 \mathrm{R}$ & $0: 10$ & - & - & - & - \\
\hline Huashuang 5(S): & $1: 9$ & 0.57 & 0.06 & 0.88 & 0.54 \\
\hline \multirow[t]{3}{*}{ Huashuang 5R(R) } & $2: 8$ & 0.81 & 0.04 & 0.90 & 0.56 \\
\hline & $3: 7$ & 0.57 & 0.05 & 0.92 & 0.56 \\
\hline & $10: 0$ & - & - & - & - \\
\hline 华油杂 62 号:华油杂 $62 \mathrm{R}$ & $0: 10$ & - & - & - & - \\
\hline Huayouza 62(S): & $1: 9$ & 0.57 & 0.36 & 0.27 & 0.73 \\
\hline \multirow[t]{3}{*}{ Huayouza 62R(R) } & $2: 8$ & 0.56 & 0.21 & 0.52 & 0.55 \\
\hline & $3: 7$ & 0.62 & 0.41 & 0.52 & 0.50 \\
\hline & 10:0 & - & - & - & - \\
\hline
\end{tabular}

“_”表示无数值。“_” means no data available. 


\section{2 不同比例混播对油菜产量及产量构成的影响}

从各试验点油菜产量可看出(表 3)，2017-2018 年度, 安徽绩溪试验点根肿病危害程度高于云南临 翔试验点。在安徽绩溪试验点, 华双 5 号及华油杂 62 单播时, 产量均为 $0 \mathrm{~kg} \mathrm{hm}^{-2}$, 而在云南临翔试 验点, 两品种产量分别为 $2579.1 \mathrm{~kg} \mathrm{hm}^{-2}$ 、 $2527.3 \mathrm{~kg} \mathrm{hm}^{-2}$ 。这与发病的情况是吻合的, 临翔试 验点根肿病发病较轻。与华双 5 号、华油杂 62 品种 及华双 $5 R$ 、华油杂 $62 R$ 单播相比, 2 个试验点的感、 抗品种混播均较好地稳定了根肿病区的油菜产量
(表 3); 3 种混播比例处理的产量均略低于华双 $5 \mathrm{R}$ 、 华油杂 $62 \mathrm{R}$ 单播的产量, 但均显著高于华双 5 号、 华油杂 62 品种单播的产量。

成熟期实际密度及单株产量是小区实际产量的 重要构成因素。各处理发病率不同，导致处理间成 熟期实际收获株数显著不同。总体而言, 各处理实 际收获株数随感病品种混播比例增加而减少。但单 株生长具有一定调节能力, 实际收获株数减少, 单 株角果数增加, 单株产量略增。因此, 在本试验的密 度范围内, 小区产量变化较小。

表 3 不同混播处理下的油菜产量及产量构成

Table 3 Yield and yield components under different treatments in Jixi and Linxiang

\begin{tabular}{|c|c|c|c|c|c|c|c|c|}
\hline $\begin{array}{c}\text { 组合 } \\
\text { Combination }\end{array}$ & $\begin{array}{l}\text { 地点 } \\
\text { Place }\end{array}$ & $\begin{array}{c}\text { 比例 } \\
\text { Proportion }\end{array}$ & $\begin{array}{c}\text { 产量 } \\
\text { Yield } \\
\left(\mathrm{kg} \mathrm{hm}^{-2}\right)\end{array}$ & $\begin{array}{c}\text { 实收密度 } \\
\text { Density } \\
\left(\times 10^{4} \text { plants } \mathrm{hm}^{-2}\right)\end{array}$ & $\begin{array}{c}\text { 单株产量 } \\
\text { Yield per } \\
\text { plant } \\
\left(\mathrm{g} \mathrm{plant}^{-1}\right) \\
\end{array}$ & $\begin{array}{c}\text { 单株角果数 } \\
\text { Silique no. } \\
\text { per plant }\end{array}$ & $\begin{array}{l}\text { 每角果粒数 } \\
\text { Seed no. per } \\
\text { silique }\end{array}$ & $\begin{array}{c}\text { 千粒重 } \\
\text { 1000-seed } \\
\text { weight (g) }\end{array}$ \\
\hline 华双 5 号:华双 5 号 R & 绩溪 & $0: 10$ & $2719.5 \mathrm{a}$ & $28.1 \mathrm{a}$ & $11.5 \mathrm{~b}$ & $176.0 \mathrm{~b}$ & $18.8 \mathrm{~b}$ & $3.48 \mathrm{~d}$ \\
\hline \multirow{9}{*}{$\begin{array}{l}\text { Huashuang 5(S): } \\
\text { Huashuang 5R(R) }\end{array}$} & Jixi & $1: 9$ & $2545.5 \mathrm{ab}$ & $26.9 \mathrm{a}$ & $12.6 \mathrm{ab}$ & $181.7 \mathrm{ab}$ & $19.9 \mathrm{a}$ & $3.53 \mathrm{c}$ \\
\hline & & $2: 8$ & $2506.5 \mathrm{ab}$ & $22.7 \mathrm{~b}$ & $13.5 \mathrm{a}$ & $187.3 \mathrm{ab}$ & $20.0 \mathrm{a}$ & $3.61 \mathrm{a}$ \\
\hline & & $3: 7$ & $2466.0 \mathrm{~b}$ & $22.1 \mathrm{~b}$ & $13.7 \mathrm{a}$ & $192.7 \mathrm{a}$ & $20.1 \mathrm{a}$ & $3.58 \mathrm{~b}$ \\
\hline & & $10: 0$ & $0 \mathrm{c}$ & $0 \mathrm{c}$ & $0 \mathrm{c}$ & $0 \mathrm{c}$ & $0 \mathrm{c}$ & $0 \mathrm{e}$ \\
\hline & 临翔 & $0: 10$ & $3019.5 \mathrm{a}$ & $30.1 \mathrm{a}$ & $10.8 \mathrm{c}$ & $187.0 \mathrm{~d}$ & $19.6 \mathrm{~b}$ & $2.95 \mathrm{~b}$ \\
\hline & Linxiang & $1: 9$ & $2981.4 \mathrm{a}$ & $29.2 \mathrm{a}$ & $11.2 \mathrm{~b}$ & $194.7 \mathrm{~b}$ & $20.1 \mathrm{ab}$ & $2.87 \mathrm{~b}$ \\
\hline & & $2: 8$ & $2938.2 \mathrm{a}$ & $26.7 \mathrm{~b}$ & $14.3 \mathrm{a}$ & $190.7 \mathrm{c}$ & $20.6 \mathrm{ab}$ & $3.63 \mathrm{a}$ \\
\hline & & $3: 7$ & $2846.7 \mathrm{a}$ & $26.0 \mathrm{~b}$ & $14.5 \mathrm{a}$ & $202.3 \mathrm{a}$ & $21.0 \mathrm{a}$ & $3.41 \mathrm{a}$ \\
\hline & & $10: 0$ & $2579.1 \mathrm{~b}$ & $24.7 \mathrm{c}$ & $10.6 \mathrm{c}$ & $149.7 \mathrm{e}$ & $19.4 \mathrm{~b}$ & $3.65 \mathrm{a}$ \\
\hline 华油杂 62 号:华油杂 $62 \mathrm{R}$ & 绩溪 & $0: 10$ & $3383.3 \mathrm{a}$ & $25.7 \mathrm{a}$ & $13.2 \mathrm{~b}$ & $180.7 \mathrm{~b}$ & $20.6 \mathrm{c}$ & $3.54 \mathrm{~b}$ \\
\hline Huayouza 62(S): & Jixi & $1: 9$ & $3142.2 \mathrm{ab}$ & $22.3 \mathrm{~b}$ & $14.1 \mathrm{a}$ & $186.5 \mathrm{a}$ & $21.2 \mathrm{~b}$ & $3.57 \mathrm{~b}$ \\
\hline \multirow[t]{8}{*}{ Huayouza 62R(R) } & & $2: 8$ & $2904.4 \mathrm{~b}$ & $20.8 \mathrm{~b}$ & $13.9 \mathrm{ab}$ & $176.0 \mathrm{c}$ & $21.6 \mathrm{~b}$ & $3.68 \mathrm{a}$ \\
\hline & & $3: 7$ & $3092.2 \mathrm{~b}$ & $20.7 \mathrm{~b}$ & $14.9 \mathrm{a}$ & $180.0 \mathrm{~b}$ & $22.7 \mathrm{a}$ & $3.66 \mathrm{a}$ \\
\hline & & $10: 0$ & $0 \mathrm{c}$ & $0 \mathrm{c}$ & $0 \mathrm{c}$ & $0 \mathrm{~d}$ & $0 \mathrm{~d}$ & $0 \mathrm{c}$ \\
\hline & 临翔 & $0: 10$ & $3413.7 \mathrm{a}$ & $31.5 \mathrm{a}$ & $10.8 \mathrm{~b}$ & $180.7 \mathrm{c}$ & $19.4 \mathrm{a}$ & $3.08 \mathrm{~b}$ \\
\hline & Linxiang & $1: 9$ & $3158.8 \mathrm{~b}$ & $28.1 \mathrm{~b}$ & $11.3 \mathrm{a}$ & $191.7 \mathrm{a}$ & $19.2 \mathrm{a}$ & $3.07 \mathrm{~b}$ \\
\hline & & $2: 8$ & $3058.1 \mathrm{~b}$ & $28.5 \mathrm{~b}$ & $10.7 \mathrm{~b}$ & $184.5 \mathrm{~b}$ & $19.2 \mathrm{a}$ & $3.02 \mathrm{c}$ \\
\hline & & $3: 7$ & $2776.3 \mathrm{c}$ & $28.0 \mathrm{~b}$ & $9.9 \mathrm{c}$ & $177.2 \mathrm{~d}$ & $18.5 \mathrm{~b}$ & $3.02 \mathrm{c}$ \\
\hline & & $10: 0$ & $2527.3 \mathrm{~d}$ & $26.6 \mathrm{~b}$ & $9.5 \mathrm{c}$ & $160.5 \mathrm{e}$ & $18.5 \mathrm{~b}$ & $3.20 \mathrm{a}$ \\
\hline
\end{tabular}

同一列平均数后的不同字母表示在 $P<0.05$ 水平差异显著。

Means followed by different lowercase letters in the same column are significantly different at the 0.05 probability level.

\section{3 对籽粒品质的影响}

2.3.1 含油量和蛋白质含量 油料作物种子含油 量与加工企业经济效益密切相关。因此, 油菜种子 的含油量是其重要的品质指标。含油量由品种特性 及环境条件所决定。就本试验而言, 安徽绩溪试验 点各处理条件下的种子含油量均略高于云南临翔试 验点; 华双 5 号感、抗根肿病近等基因系的含油量
(48.30\% 49.31\%)也略高于华油杂 62 感、抗根肿病 近等基因系(45.05\% 46.22\%)。就各处理而言，随着 感病品种混播比例的增加, 在 2 个试验点, 两组感、 抗近等基因系组合的种子含油量差异较小, 大多数 处理间差异未达显著水平。表明本试验条件下，感、 抗品种混播后, 籽粒含油量以及蛋白质含量指标均 较为稳定。 
表 4 不同混播处理下的油菜籽粒含油量及蛋白质含量

Table 4 Difference of rapeseed quality under different treatments in Jixi and Linxiang (\%)

\begin{tabular}{|c|c|c|c|c|c|}
\hline \multirow{2}{*}{$\begin{array}{c}\text { 组合 } \\
\text { Combination }\end{array}$} & \multirow{2}{*}{$\begin{array}{l}\text { 比例 } \\
\text { Ratio }\end{array}$} & \multicolumn{2}{|c|}{ 绩溪 Jixi } & \multicolumn{2}{|c|}{ 临翔 Linxiang } \\
\hline & & $\begin{array}{c}\text { 含油量 } \\
\text { Oil content }\end{array}$ & $\begin{array}{l}\text { 蛋白质 } \\
\text { Protein }\end{array}$ & $\begin{array}{c}\text { 含油量 } \\
\text { Oil content }\end{array}$ & $\begin{array}{l}\text { 蛋白质 } \\
\text { Protein }\end{array}$ \\
\hline 华双 5 号:华双 5 号 $\mathrm{R}$ & $0: 10$ & $48.30 \mathrm{a}$ & $21.17 \mathrm{a}$ & $44.16 \mathrm{~b}$ & $23.25 \mathrm{a}$ \\
\hline \multirow[t]{4}{*}{ Huashuang 5(S) : Huashuang 5R(R) } & $1: 9$ & $49.31 \mathrm{a}$ & $20.71 \mathrm{a}$ & $44.59 \mathrm{ab}$ & $22.44 \mathrm{ab}$ \\
\hline & $2: 8$ & $49.05 \mathrm{a}$ & $19.22 \mathrm{a}$ & $45.65 \mathrm{a}$ & $21.96 \mathrm{~b}$ \\
\hline & $3: 7$ & $48.61 \mathrm{a}$ & $19.00 \mathrm{a}$ & $44.60 \mathrm{ab}$ & $21.98 \mathrm{~b}$ \\
\hline & $10: 0$ & - & - & $44.88 \mathrm{ab}$ & $22.60 \mathrm{ab}$ \\
\hline 华油杂 62 号:华油杂 $62 \mathrm{R}$ & $0: 10$ & $45.12 \mathrm{a}$ & $20.26 \mathrm{a}$ & $42.04 \mathrm{~b}$ & $25.21 \mathrm{a}$ \\
\hline \multirow[t]{4}{*}{ Huayouza 62(S) : Huayouza 62R(R) } & $1: 9$ & $45.05 \mathrm{a}$ & $20.24 \mathrm{a}$ & $42.20 \mathrm{ab}$ & $24.08 \mathrm{a}$ \\
\hline & $2: 8$ & $45.91 \mathrm{a}$ & $19.15 \mathrm{a}$ & $42.31 \mathrm{ab}$ & $24.34 \mathrm{a}$ \\
\hline & $3: 7$ & $46.22 \mathrm{a}$ & $19.06 \mathrm{a}$ & $43.22 \mathrm{a}$ & $24.28 \mathrm{a}$ \\
\hline & 10:0 & - & - & $43.07 \mathrm{ab}$ & $24.33 \mathrm{a}$ \\
\hline
\end{tabular}

“一”表示无数值。同一列平均数后的不同字母表示在 $P<0.05$ 水平差异显著。

“- " means no data available. Means followed by different lowercase letters in the same column are significantly different at the 0.05 probability level.

2.3.2 籽粒游离氨基酸含量 测定了籽粒中 16 种氨基酸的含量, 安徽绩溪点感病品种单播处理 (10：0)因发病严重无法收获籽粒而未测定。表 5 表 明, 油菜籽粒的 Glu 含量最高, Met 含量最低。将 16
种氨基酸分为中性、碱性和酸性 3 类。其中，中性 氨基酸 Phe、Lle、Thr、Ser 和 Met 含量及碱性氨基 酸 Lys 和 Arg 含量在混播与单播中差异显著。在安 徽绩溪试验点, 华双 $5 \mathrm{R}$ 单播和 $3: 7$ 混播处理的 16

表 5 华双 5 号:华双 5 号 $\mathbf{R}$ 组合不同混播处理下籽粒氨基酸含量

Table 5 Amino acid content in rapeseed under different treatments for Huashuang 5(S):Huashuang 5R(R)

\begin{tabular}{|c|c|c|c|c|c|c|c|c|}
\hline \multirow{3}{*}{\multicolumn{2}{|c|}{$\begin{array}{c}\text { 氨基酸 } \\
\text { Amino acid }\end{array}$}} & \multicolumn{3}{|c|}{ 绩溪 Jixi } & \multicolumn{4}{|c|}{ 临翔 Linxiang } \\
\hline & & \multicolumn{2}{|c|}{ 比例 Ratio } & \multirow{2}{*}{$\begin{array}{c}\text { 变异系数 } \\
\text { CV (\%) }\end{array}$} & \multicolumn{3}{|c|}{ 比例 Ratio } & \multirow{2}{*}{$\begin{array}{c}\text { 变异系数 } \\
\text { CV }(\%)\end{array}$} \\
\hline & & $0: 10$ & $3: 7$ & & $0: 10$ & $3: 7$ & $10: 0$ & \\
\hline 中性 & Phe & 0.82 & $0.80^{*}$ & 1.51 & $0.90 \mathrm{ab}$ & $0.86 \mathrm{~b}$ & $0.92 \mathrm{a}$ & 3.51 \\
\hline \multirow[t]{10}{*}{ Neutral } & Lle & 0.81 & $0.78^{*}$ & 2.07 & $0.85 \mathrm{ab}$ & $0.82 \mathrm{~b}$ & $0.88 \mathrm{a}$ & 3.87 \\
\hline & Thr & 0.75 & $0.70^{*}$ & 3.58 & $0.73 \mathrm{~b}$ & $0.67 \mathrm{c}$ & $0.85 \mathrm{a}$ & 10.27 \\
\hline & Ser & 0.61 & $0.56^{*}$ & 6.11 & $0.53 \mathrm{~b}$ & $0.44 \mathrm{~b}$ & $0.74 \mathrm{a}$ & 22.50 \\
\hline & Met & 0.25 & $0.23^{*}$ & 3.49 & $0.23 \mathrm{~b}$ & $0.24 \mathrm{~b}$ & $0.25 \mathrm{a}$ & 3.15 \\
\hline & Val & 1.03 & $1.00^{*}$ & 1.85 & $1.14 \mathrm{a}$ & $1.12 \mathrm{a}$ & $1.15 \mathrm{a}$ & 2.73 \\
\hline & Leu & 1.26 & 1.24 & 1.20 & $1.40 \mathrm{ab}$ & $1.33 \mathrm{~b}$ & $1.44 \mathrm{a}$ & 4.54 \\
\hline & Tyr & 0.52 & 0.52 & 1.60 & $0.52 \mathrm{a}$ & $0.48 \mathrm{c}$ & $0.60 \mathrm{a}$ & 9.61 \\
\hline & Pro & 1.19 & 1.19 & 1.92 & $1.40 \mathrm{a}$ & $1.30 \mathrm{~b}$ & $1.33 \mathrm{~b}$ & 3.76 \\
\hline & Gly & 1.02 & 1.00 & 1.08 & $1.11 \mathrm{a}$ & $1.07 \mathrm{a}$ & $1.10 \mathrm{a}$ & 2.88 \\
\hline & Ala & 0.85 & 0.84 & 1.54 & $0.96 \mathrm{a}$ & $0.93 \mathrm{a}$ & $0.95 \mathrm{a}$ & 2.18 \\
\hline 碱性 & Lys & 1.38 & $1.35^{*}$ & 1.20 & $1.51 \mathrm{a}$ & $1.40 \mathrm{~b}$ & $1.53 \mathrm{a}$ & 4.62 \\
\hline \multirow[t]{2}{*}{ Basic } & Arg & 1.22 & $1.16^{*}$ & 2.41 & $1.43 \mathrm{a}$ & $1.34 \mathrm{~b}$ & $1.46 \mathrm{a}$ & 3.71 \\
\hline & His & 0.61 & $0.57^{*}$ & 3.48 & $0.64 \mathrm{a}$ & $0.62 \mathrm{a}$ & $0.63 \mathrm{a}$ & 5.42 \\
\hline 酸性 & Glu & 3.37 & 3.46 & 3.00 & $3.89 \mathrm{a}$ & $3.65 \mathrm{~b}$ & $3.65 \mathrm{~b}$ & 3.72 \\
\hline Acidic & Asp & 1.36 & $1.29^{*}$ & 2.69 & $1.55 \mathrm{a}$ & $1.49 \mathrm{a}$ & $1.54 \mathrm{a}$ & 2.72 \\
\hline \multicolumn{2}{|c|}{ 总量 Total } & 17.00 & 16.66 & - & 18.74 & 17.74 & 18.97 & \\
\hline
\end{tabular}

“一”表示无数值。“表示在绩溪试验点在种植比例 $0: 1$ 和 3:7 时差异显著 $(P<0.05)$; 平均值后的不同字母表示在临翔试验点 3 个处理间 差异显著 $(P<0.05)$ 。

“- means no item. ${ }^{*}$ indicates significant difference of different treatments at the 0.05 probability level in Jixi. Means followed by different lowercase letters in the same column are significantly different at the 0.05 probability level in Linxiang. 
种氨基酸的变异系数均小于 $10 \%$, 表明与抗病品种 单播相比, 混播对各类氨基酸影响较小。而在云南 临翔试验点, 华双 $5 \mathrm{R}$ 单播和华双 5 号单播与 $3: 7$ 混播处理间 Ser 含量较其他氨基酸差异明显, 变异 系数达到 $22.5 \%$, 且感病品种籽粒中 Ser 含量最高。

\section{3 讨论}

近年来, 油菜根肿病在我国呈蔓延趋势, 严重 威胁到我国油菜的安全生产。前人在根肿病的防治 上开展了大量的研究, 包括农业、化学及生物等防 控措施, 但选用抗病品种依然是最经济、高效、环 境友好的手段。然而, 抗性品种的单一抗性丧失是 潜在隐患。预防抗性品种的抗性丧失目前主要有 2 种方式，一是从遗传分子水平上培育对根肿病具有 广谱且持久抗性的品种, 二是利用栽培模式维持抗 性品种的持久抗性。华双 $5 \mathrm{R}$ 和华油杂 $62 \mathrm{R}$ 是我国 最先培育的 2 个抗根肿病油菜品种, 抗性均为少 数基因控制的质量性状，其抗病基因分别为 $P b B a 8.1$ 和 $C R b$ 。这 2 个品种对我国根肿病优势生 理小种-4 号生理小种均具较好抗性, 但这类专 一抗性品种对根肿菌有高度选择压力, 极可能导致 其他生理小种或变异生理小种转为新的优势小种, 导致品种抗性丧失。较多研究表明, 感、抗品种混 播, 不仅可提高感病品种抗性, 其主要的防控机理 有密度效应 ${ }^{[23]}$ 、阻挡效应 ${ }^{[24]}$ 和抗性诱导效应 ${ }^{[25]}$ 。此 外, 还可避免生理小种的高度选择压力 ${ }^{[29]}$, 即寄主 的多样性有利于寄主与病原菌群体之间的协同进 化, 稳定病原菌群体结构 ${ }^{[26]}$ 。但在油菜根肿病研究 领域尚未见相关报道。本研究在我国 2 个油菜根肿 病典型区域设置试验, 初步研究混播对油菜根肿病 发病率、产量的影响, 为我国根肿病区油菜生产提 供了技术支撑。

2 个感病品种单播时, 绩溪试验点的发病率要 高于临翔试验点, 这是因为当年绩溪试验点的气候 有利于根肿病的发生。此外, 因为气候条件差异, 2 个试验点的油菜长势也存在一定差异, 因此对于根 肿病的抵抗能力也存在差别。在 2 个根肿病危害地 区, 感病、抗病品种混播后, 田间实际发病率均小于 理论发病率, REM 值亦小于 1 。表明在生产中采用 感、抗根肿病油菜品种按一定比例混播防控油菜根 肿病是可行的。在 2 个试验点均为第 2 次调查的 REM 值小于第 1 次调查, 表明感、抗品种混播可在 时间上延迟根肿病的发展速度, 可明显减轻二次侵
染。当然, REM 值降低, 另一个原因是, 随着生育进 程苗期发病较重的一些植株会死亡, 而健康植株的 数量变化不大, 因此对于同一组品种而言, 生育后 期的 REM 值均低于生育前期。

油菜全生育期都会感染根肿病。病害发生后, 油菜单株角果数、每角果粒数和千粒重均显著降 低 ${ }^{[30]}$, 产量损失可达 $80 \% \sim 90 \%{ }^{[31]}$ 。在欧洲，病情指 数每增加 $1 \%$, 油菜籽产量损失 $0.03 \mathrm{t} \mathrm{hm}^{-2}$ [32]。密度 与单株产量是作物群体产量的重要构成因素。本试 验中, 感、抗品种混播后, 密度会有一定程度降低。 一般而言, 密度增加, 个体竞争加剧, 油菜单株产 量降低 ${ }^{[33]}$; 而密度降低, 单株角果数增加, 单株产 量提高。在本试验的播种量(每公顷用种量 $3.75 \mathrm{~kg}$ ) 条件下, 种植密度与单株产量协调较好, 因此各处 理均有较高的籽粒产量。且与感病品种相比, 抗病 品种以及感、抗品种混播, 均在一定程度上提高了 籽粒含油量。

不同混播处理下籽粒中某些游离氨基酸含量差 异显著。其中, 以丝氨酸(Ser)含量变化最大, 且感病 品种中 Ser 含量最高。前人研究表明, Ser 极有可能 与根肿菌致病性有关, 或作为根肿菌与寄主的相互 作用的一个信号分子。抗病基因的编码产物丝氨酸/ 苏氨酸激酶催化其底物蛋白丝氨酸磷酸化，在抗病 反应信号传导中起重要作用 ${ }^{[34]}$ 。从大白菜根瘤根肿 菌分离出一种新的丝氨酸/苏氨酸激酶基因 PbSTKL1，该基因在根肿病形成期间大量表达 ${ }^{[35]}$ 。 MAPKK (丝裂原活化蛋白激酶激酶)也作用于底物 蛋白丝氨酸的磷酸化完成信号转导途径。研究发现 MAPKK 抑制剂 U0126 能抑制根肿菌休眠狍子萌发, MAPK (丝裂原活化蛋白激酶)级联途径可能对根肿 菌生长和致病性起重要作用 ${ }^{[36]}$ 。丝氨酸蛋白酶基因 (Pro1)作为根肿菌的致病因子, 在感病期间 Prol 转 录本丰度增加, Prol 活性增强可以促进休眠孢子的 萌发 ${ }^{[37]}$ 。本试验中, 种子 Ser 含量的差异是如何受到 根系中相关基因表达影响的，还有待进一步研究。

混播后，感病品种发病率下降，其原因可能是 抗病品种的抗性诱导效应和密度效应。抗根肿病品 种的抗性反应是由 $\mathrm{R}$ 蛋白介导的免疫防御反应, $\mathrm{R}$ 蛋 白与根肿菌分泌的效应蛋白特异性识别与互作诱导 产生防御反应。水稻近等基因系混播中的诱导抗性 机制抑制了稻瘟病。Pi-k 系和 Pi-i 系品种混播后一 并接种 7 号和 33 号稻瘟病菌小种, 其中 Pi-k 系抗 7 号小种, 感 33 号小种, 而 Pi-i 系抗 33 号小种, 感 7 
号小种。最终接种无毒性和毒性小种混播的病情程 度低于只接种毒性小种的混播 ${ }^{[38]}$ 。病原菌-植物互作 会引起植物的化感作用 ${ }^{[39]}$ 。根肿菌激活抗病品种的 免疫反应, 在根肿菌-抗病植物互作这一过程中, 抗 病品种释放出某些具有活性的次生代谢产物, 进而 影响邻近的感病品种。由于根系分泌出的化感物质 所到达的范围有限, 所以混播效果极大可能与密度 有关, 即密度效应。

\section{4 结论}

在油菜根肿病高发地区, 与感病品种单播相比, 油菜感、抗根肿病品种混播减轻了根肿病病情, 获 得了较稳定的籽粒产量与品质; 且选择与高抗品种 混播效果优于中抗品种, 该技术为我国根肿病区油 菜生产提供了可供选择的技术措施。

\section{References}

[1] Dixon G R. Clubroot (Plasmodiophora brassicae Woronin): an agricultural and biological challenge worldwide. Can J Plant Pathol, 2014, 36(S1): 5-18.

[2] Kageyama K, Asano T. Life cycle of Plasmodiophora brassicae. J Plant Growth Regul, 2009, 28: 203-211.

[3] Devos S, Vissenberg K, Verbelen J P, Prinsen E. Infection of Chinese cabbage by Plasmodiophora brassicae leads to a stimulation of plant growth: impacts on cell wall metabolism and hormone balance. New Phytol, 2010, 166: 241-250.

[4] Ludwing-Müller J, Prinsen E, Rolfe S A, Scholes J D. Metabolism and plant hormone action during clubroot disease. J Plant Growth Regul, 2009, 28: 229-244.

[5] Dixon G R. The occurrence and economic impact of Plasmodiophora brassicae and clubroot disease. J Plant Growth Regul, 2009, 28: 194-202.

[6] Chai A L, Xie X W, Shi Y X, Li B J. Research status of clubroot (Plasmodiophora brassicae) on cruciferous crops in China. Can J Plant Pathol, 2014, 36(S1): 142-153.

[7] Peng G, Pageau D, Strelkov S E, Grossen B D, Hwang S F, Lahlali R. A $>2$-year crop rotation reduces resting spores of Plasmodiophora brassicae in soil and the impact of clubroot on canola. Eur J Agron, 2015, 70: 78-84.

[8] Friberg H, Lagerlöf J, Rämert B. Germination of Plasmodiophora brassicae resting spores stimulated by a non-host plant. Eur $J$ Plant Pathol, 2005, 113: 275-281.

[9] 费维新, 王淑芬, 李强生, 吴晓芸, 陈凤祥, 侯树敏, 荣松柏, 郝仲萍, 高智谋. 冬油菜适当迟播有效减轻油菜根肿病. 中国 油料作物学报, 2016, 38: 502-507.

Fei W X, Wang S F, Li Q S, Wu X Y, Chen F X, Hou S M, Rong S B, Hao Z P, Gao Z M. Reducing clubroot disease by late sowing of winter rapeseed. Chin J Oil Crop Sci, 2016, 38: 502-507 (in Chinese with English abstract).

[10] Niwa R, Kumei T, Nomura Y, Yoshida S, Osaki M, Ezawa T. Increase in soil $\mathrm{pH}$ due to Ca-rich organic matter application causes suppression of the clubroot disease of crucifers. Soil Biol Biochem, 2007, 39: 778-785.

[11] 杨进, 殷丽琴, 王晓, 付绍红, 王学贵, 李云, 王继胜, 刍琼, 陶兰荣, 康泽明, 唐蓉. 4 种杀菌剂对油菜根肿病的防治潜力 及对幼苗防御酶活性的影响. 中国油料作物学报, 2017, 39: 546-550.

Yang J, Yin L Q, Wang X, Fu X H, Wang X G, Li Y, Wang J S, Zou Q, Tao L R, Kang Z M, Tang R. Preventive potential of 4 fungicids on clubroot (Plasmodiophora brassicae) and rapeseed defense enzyme activity. Chin J Oil Crop Sci, 2017, 39: 546-550 (in Chinese with English abstract).

[12] 陈坤荣, 任莉, 刘凡, 徐理, 孙超超, 方小平. 三种杀菌剂防 治油菜根肿病技术研究. 中国油料作物学报, 2013, 35: 424-427.

Chen K R, Ren L, Liu F, Xu L, Sun C C, Fang X P. Controlling effects of three fungicides on rapeseed clubroot. Chin J Oil Crop Sci, 2013, 35: 424-427 (in Chinese with English abstract).

[13] 王王靖, 黄云, 张艳, 张艳, 姚佳. 油菜根肿病菌拮抗微生物 的筛选及其防治效果测定. 中国油料作物学报, 2011，33: 169-174.

Wang J, Huang Y, Zhang Y, Yao J. Control of rapeseed clubroot by screened antagonistic against Plasmodiophora brassicae. Chin J Oil Crop Sci, 2011, 33: 169-174 (in Chinese with English abstract).

[14] Liu C M, Yang Z F, He P F, Munir S, Wu Y X, Ho H H, He Y Q. Deciphering the bacterial and fungal communities in clubroot-affected cabbage rhizosphere treated with Bacillus subtilis XF-1. Agric Ecosyst Environ, 2018, 256: 12-22.

[15] Peng G, Falk K C, Gugel R K, Franke C, Yu F Q, James B, Strelkov S E, Hwang S F, Gregor L M. Sources of resistance to Plasmodiophora brassicae (clubroot) pathotypes virulent on canola. Can J Plant Pathol, 2014, 36: 89-99.

[16] 战宗祥, 江荣芬, 朱紫媛, 张春沙, 杨庆勇, 李倩, 侯照科, 龚 建芳, 程雨贵, 吴江生, 傅廷栋, 周永明, 朴钟云, 张椿雨. 与 位点 PbBa8.1 紧密连锁分子标记的开发及甘蓝型油菜根肿病 抗性育种. 中国油料作物学报, 2015, 37: 766-771.

Zhan Z X, Jiang Y F, Zhu Z Y, Zhang C S, Yang Q Y, Li Q, Hou Z K, Gong J F, Cheng Y G, Wu J S, Fu T D, Zhou Y M, Piao Z Y, Zhan C Y. Development of close linked marker to PbBa8.1 conferring canola resistance to Plasmodiophora brassicae. Chin J Oil Crop Sci, 2015, 37: 766-771 (in Chinese with English abstract).

[17] Wallenhammar A C. Prevalence of Plasmodiophora brassicae in a spring oilseed rape growing area in central Sweden and factors influencing soil infestation levels. Plant Pathol, 1996, 45: 710-719.

[18] Diederichsen E, Frauen M, Ludwing-Müller J. Clubroot disease management challenges from a German perspective. Can J Plant Pathol, 2014, 36(S1): 85-98.

[19] 吕学静, 康晓慧, 陈万权, 刘太国, 刘博, 高利. 小麦近等基 因系多品种混播对条锈病控制效果研究. 中国植保导刊, 2014, 34(4): 5-9.

Lyu X J, Kang X H, Chen W Q, Liu T G, Liu B, Gao L. Controlling efficiency against wheat stripe rust by near-isogenic lines cultivarsa at mix-planting condition. China Plant Protect, 2014, 34(4): 5-9. 
[20] 刘志贤, 肖一龙, 刘二明, 罗峰. 利用水稻品种抗性遗传多样 性持续控制稻瘟病研究进展. 作物研究, 2003, 17(2): 103-105.

Liu Z X, Xiao Y L, Liu E M, Luo F. Advances in susyainable control of rice blast by using composite varieties resistant to different physiologic race blast diseases. Crop Res, 2003, 17(2): 103-105 (in Chinese with English abstract).

[21] Hariri D, Fouchard M, Prud'homme H. Incidence of soil-borne wheat mosaic virus in mixtures of susceptible and resistant wheat cultivars. Eur J Plant Pathol, 2001, 107: 625-631.

[22] 郭世保, 黄丽丽, 康振生, 程晶晶, 陆宁海, 杨之为, 陈银潮. 小麦多品种混播控制条锈病的效果和机理研究. 中国农业科 学, 2009, 42: 3485-3492.

Guo S B, Huang L L, Kang Z S, Cheng J J, Lu N H, Yang Z W, Chen Y C. Efficacy and mechanism of control of wheat stripe rust by diversifying cultivars in mix-planting. Sci Agric Sin, 2009, 42: 3485-3492 (in Chinese with English abstract).

[23] Burdon J J, Chilvers G A. Host density as a factor in plant disease ecology. Annu Rev Phytopathol, 1982, 20: 143-166.

[24] Trenbath B R. Interactions among diverse hosts and diverse parasites. Ann NY Acad Sci, 2010, 287: 124-150.

[25] Zhu Y Y, Chen H R, Fan J H, Wang Y Y, Li Y, Chen J B, Fan J X, Yang S S, Hu L P, Leung H, Mew T W, Teng P S, Wang Z H, Mundt C C. Genetic diversity and disease control in rice. Nature, 2000, 406: 718-722.

[26] 李宁. 寄主多样性条件下小麦白粉病发生及其病原菌群体遗 传结构的研究. 中国农业科学院硕士学位论文, 北京, 2011.

Li N. Occurrence of Wheat Powdery Mildew in Diversified Hosts and the Pathogen Population Genetic Structure. MS Thesis of Chinese Academy of Agricultural Sciences, Beijing, China, 2011 (in Chinese with English abstract).

[27] Kuginuki Y, Hiroaki Y, Hirai M. Variation in virulence of Plasmodiophora brassicae in Japan tested with clubroot-resistant cultivars of Chinese cabbage (Brassica rapa L. spp. pekinensis). Eur J Plant Pathol, 1999, 105: 327-332.

[28] 黄冲, 郭洁滨, 孙振宇, 马占鸿, 刘跃富, 陈伦开. 小麦品种 混(间)种对小麦条锈病防治效果和产量影响研究. 植物保护, 2009, 35(3): 115-117.

Huang C, Guo J B, Sun Z Y, Ma Z H, Liu Y F, Chen L K. Studies on the effects of cultivar mixtures or multiline cultivals on the wheat yeIlow rust and wheat yield under different pathogenesis oonditions. Plant Protect, 2009, 35(3): 115-117 (in Chinese with English abstract).

[29] Sapoukhina N, Paillard S, Dedryver F, Vallavieille-Pope C. Quantitative plant resistance in cultivar mixtures: wheat yellow rust as a modeling case study. New Phytol, 2013, 200: 888-897.
[30] 王靖, 黄云, 胡晓玲, 牛应泽, 李晓兰, 梁勇. 油菜根肿病症状、病 原形态及产量损失研究. 中国油料作物学报, 2008, 30: 112-115.

Wang J, Huang Y, Hu X L, Niu Y Z, Li X L, Liang Y. Study on symptom, yield loss of clubroot and modality of Plasmodiophora brassicae in rape. Chin J Oil Crop Sci, 2008, 30: 112-115 (in Chinese with English abstract).

[31] Pageau D, Lajeunesse J, Lafond J. Impact of clubroot (Plasmodiophora brassicae) on the yield and quality of canola. Can $J$ Plant Pathol. 2006, 28: 137-143.

[32] Mcgrann G R D, Gladders P, Smith J A, Burnett F. Control of clubroot (Plasmodiophora brassicae) in oilseed rape using varietal resistance and soil amendments. Field Crops Res, 2016, 186: 146-156.

[33] Leach J A, Stevenson H J, Rainbow A J, Mullen L A. Effects of high plant populations on the growth and yield of winter oilseed rape (Brassica napus). J Agric Sci, 1999, 132: 173-180.

[34] 杜中军, 王家保, 黄俊生, 翟衡, 徐兵强. 番木瓜丝氨酸/苏氨 酸蛋白激酶类抗病基因同源序列的克隆与特征分析. 果树学 报, 2006, 23: 46-50.

Du Z J, Wang J B, Huang J S, Zhai H, Xu B Q. Isolation and characterization of serine/threonine protein kinase-like disease resistance gene analogs from papaya (Carica papaya). J Fruit Sci, 2006, 23: 46-50 (in Chinese with English abstract).

[35] Ando S, Yamada T, Asano T, Kamachi S, Tsushima S, Hagio T, Tabei Y. Molecular cloning of PbSTKL1 gene from Plasmodiophora brassicae expressed during clubroot development. J Phytopathol, 2006, 154: 185-189.

[36] Chen T, Bi K, Zhao Y, Lyu X, Gao Z, Zhao Y, Fu Y, Chen J, Xie J, Jiang D. MAPKK inhibitor U0126 inhibit Plasmodiophora brassicae development. Phytopathology, 2018, 108: 711-720.

[37] Feng J, Hwang R U, Hwang S F, Strelkov S E, Gossen B D, Zhou Q X, Peng G. Molecular characterization of a serine protease Pro1 from Plasmodiophora brassicae that stimulates resting spore germination. Mol Plant Pathol, 2010, 11: 503-512.

[38] Nakajima T, Sonoda R, Yaegashi H, Saito H. Factors related to suppression of leaf blast disease with a multiline of rice cultivar Sasanishiki and its isogenic lines. Ann Phytopathol Soc Jpn, 2009, 62: 360-364.

[39] 吴林坤, 林向民, 林文雄. 根系分泌物介导下植物-土壤-微 生物互作关系研究进展与展望. 植物生态学报, 2014, 38: 298-310.

Wu L K, Lin X M, Lin W X. Advances and perspective in research on plant-soil-microbe interactions mediated by root exudates. Chin J Plant Ecol, 2014, 38: 298-310 (in Chinese with English abstract). 